\title{
OS MOVIMENTOS SOCIAIS E OS DIREITOS HUMANOS DO POVO QUILOMBOLA NO CENÁRIO DAS DECISÕES DA CORTE INTERAMERICANA
}

\author{
Daniela Mesquita Leutchuk de Cademartori ${ }^{1}$ \\ Marlise da Rosa $\mathrm{Luz}^{2}$
}

\section{RESUMO}

Este trabalho inclui reflexões a partir de uma abordagem histórica do movimento quilombola, suas conquistas e desafios na efetivação de seus direitos. Apresentam-se cinco casos levados ao conhecimento e julgamento da Corte Interamericana de Direitos Humanos envolvendo povos quilombolas do Suriname, Honduras e Colômbia. Adiante, faz-se uma abordagem sobre os movimentos sociais e a construção de direitos humanos, a partir da contribuição teórica de Maria da Glória Gohn e Joaquin Herrera Flores, com enfoque no movimento quilombola. São feitos levantamentos bibliográficos e de artigos acadêmicos, bem como, pesquisa de casos envolvendo a população negra junto a Corte IDH.

PALAVRAS-CHAVE: Quilombolas; América Latina; Direitos Humanos; Movimentos sociais; Corte Interamericana de Direitos Humanos

\section{SOCIAL MOVEMENTS AND HUMAN RIGHTS OF THE QUILOMBOLA PEOPLE IN THE SCENARIO OF DECISIONS OF THE INTER-AMERICAN COURT}

\begin{abstract}
This work includes reflections based on a historical approach to the quilombola movement, its achievements and challenges in the realization of its rights. Five cases brought to the attention and judgment of the Inter-American Court of Human Rights involving quilombola peoples from Suriname, Honduras and Colombia are presented. This is followed by an approach on social movements and the construction of human rights, based on the theoretical contribution of Maria da Glória Gohn and Joaquin Herrera Flores, with a focus on the quilombola movement. Bibliographical and academic articles are collected, as well as case studies involving the black population at the Inter-American Court.
\end{abstract}

KEY WORDS: Quilombolas; Latin America; Human Rights; Social movements; Corte Interamericana de Derechos Humanos; Inter-American Court of Human Rights

\section{INTRODUÇÃO}

O presente trabalho insere-se em um contexto de valorização da importância do movimento quilombola na construção e reconhecimento de direitos ao povo negro latinoamericano, de origem africana, trazidos para esta região na condição de escravos. Inicia-se com uma abordagem histórica do movimento negro, desde o momento da colonização, quando submetidos e escravizados, trazidos como força de trabalho em uma conjuntura de exploração das colônias pelas metrópoles europeias a partir do século XVI.

\footnotetext{
${ }^{1}$ Mestre e Doutora em Direito pela UFSC. Professora da Pós-Graduação em Direito e Sociedade (Mestrado) e da Graduação em Direito da Unilasalle Canoas/RS.

${ }^{2}$ Mestranda em Direito da Universidade La Salle - Canoas. Linha de Pesquisa: Sociedade e Fragmentação do Direito.
} 
Destaca-se ainda, que mesmo após a abolição da escravatura e, mais recentemente, pelas conquistas obtidas na década de 1980, com a inserção de direitos nas Constituições nacionais de países latino-americanos, o movimento quilombola ainda encontra grandes desafios, que inclui a real efetivação dos direitos assegurados legalmente.

Para melhor compreensão e identificação dos fatos, são apresentados cinco casos levados ao conhecimento e julgamento da Corte Interamericana de Direitos Humanos (doravante denominada de Corte IDH) e que denunciam a luta contra a invisibilidade, a discriminação e estigmatização de povos quilombolas na América Latina.

Ao fim, faz-se uma abordagem dos movimentos sociais enquanto luta pela concretização dos direitos humanos, a partir da contribuição teórica de Maria da Glória Gohn e de Joaquín Herrera Flores, com a finalidade de identificar a proximidade existente entre as duas teorias e a relevância das mesmas no fortalecimento do movimento quilombola.

Assim, a partir de uma pesquisa teórico-dedutiva, o presente trabalho propõe uma reflexão que parte de uma abordagem histórica do movimento quilombola, suas conquistas e desafios, desenvolve-se através de uma análise dos movimentos sociais e da construção de direitos humanos, com enfoque no movimento quilombola. Leva-se em consideração levantamentos bibliográficos e de artigos acadêmicos, bem como, a pesquisa de casos envolvendo a população negra junto à Corte IDH.

\section{O MOVIMENTO QUILOMBOLA NA AMÉRICA LATINA: ABORDAGEM DE RECONHECIMENTO}

A formação dos Estados latino-americanos, historicamente tem suas origens na colonização europeia. Suas instituições e atores sociais desenvolveram-se a partir de uma herança colonial, patrimonialista e escravocrata. (WOLKMER, 2015, p. 50). À exceção de algumas peculiaridades específicas, o desenvolvimento da sociedade latino-americana esteve marcada pela "exploração de territórios, a ocupação desses espaços e a opressão dos habitantes originários e dos povos que foram levados como força de trabalho para estas regiões, no caso majoritariamente os africanos escravizados.”(LÓPEZ, 2015, p.56).

Conforme ensina Antônio Carlos Wolkmer, no período da colonização da América, a formação social esteve centrada na contradição entre a elite colonizadora e a "massa de mão de obra escrava", e numa estrutura política "desvinculada dos objetivos de sua população de origem e da sociedade como um todo", funcionando com vistas ao interesse exclusivo da metrópole colonizadora. ( 2015 , p. 50).

Nesse cenário, em que o objetivo primordial da Metrópole era a exploração das riquezas encontradas na Colônia, emergiu a imigração forçada de trabalhadores africanos, trazidos não como colonos livres, mas como escravos, forçados à trabalhar no empreendimento colonizador. Por mais de três séculos, a transposição de milhões de africanos para o continente americano fez parte de um amplo projeto de exploração comercial das metrópoles europeias a partir do mercantilismo iniciado com o período das grandes navegações no século XV. (WOLKMER, 2015, p. 60)

Ou seja, a história da colonização latino-americana está inevitavelmente vinculada a da exploração da mão de obra escrava, não sendo diferente da colonização da região caribenha, uma vez que esta região era estrategicamente bem localizada para o tráfico atlântico entre a Europa e as Américas. O sistema econômico chamado mercantilismo controlado pelos europeus só foi possível graças ao tráfico atlântico que gerava intensos fluxos comerciais e populacionais entre a Europa, a África e as Américas.

Ainda que considerados pela importância na força de trabalho e na produção de riquezas nas colônias americanas, a população escravizada não foi considerada nos projetos 
de desenvolvimento das elites locais que estiveram a frente dos Estados nacionais em formação. Assim como no período colonial, as matérias legislativas da época estavam todas voltadas em "beneficiar, favorecer e defender os intentos políticos e econômicos da Metrópole", no período pós- independência a Metrópole foi substituída por elites nacionais vinculadas muitas vezes a interesses estrangeiros, tais como os ingleses. Assim, em um e outro momento, a subjugação da população era praticamente completa, pois, mesmo para os raros colonos, e principalmente para os trabalhadores escravos, os direitos repousavam na autoridade interna dos proprietários. (WOLKMER, 2015, p. 62; 64)

De outro lado, a história dos trabalhadores escravizados, subjugados à tortura, massacre e submissão, também esteve vinculada à resistência, mediante uma sobrevivência paralela, quer com os quilombos, com insurreições, levantes, fugas, etc. "O trabalhador escravizado resistiu principalmente através da fuga, sobretudo para locais de difícil acesso, onde procurava sobreviver individualmente ou em comunidade de produtores livres. No Brasil este fenômeno ficou conhecido por quilombo ou mocambo." (FIABANI, 2008, p. 53).

É neste sentido, que o presente trabalho enfatiza o estudo do movimento quilombola, ou seja, parte-se dessa designação com um sentido de luta e resistência, incluindo-se o reconhecimento de uma diversidade e complexidade de situações, seja de grupos de exescravos, seja de comunidades negras que sobreviveram conjuntamente ao longo do tempo, pretendendo-se uma interpretação não reducionista do termo quilombo como aquela interpretação antiquada que considerava apenas aqueles originários de escravos fugidos.

Os quilombos "eram organizados livremente e de forma autossuficiente, baseados na ocupação da terra, na propriedade coletiva, na agricultura de subsistência e na luta armada". (WOLKMER, 2015, p. 65). Surgiram, não exclusivamente da fuga de negros, mas também a partir de doações de terras, ou mesmo, de convivência pacífica com os proprietários de terra e de forma autônoma. (FIABANI, 2008, p.41-42).

Suas origens são variadas - algumas foram formadas por escravos (ou ex-escravos), após a falência de uma fazenda ou plantação nas décadas confusas anteriores à Abolição, algumas fruto de doações de terras por senhores a ex-escravos, outras compradas por escravos libertos (que, em alguns casos, haviam comprado sua própria liberdade), outras doações de terras a escravos que haviam servido ao exército em tempo de guerra, ou ainda doações a escravos por ordens religiosas. Em alguns casos (particularmente na região do Baixo Amazonas), elas incluem descendentes atuais de quilombos formados no período próximo ao fim da escravidão ou talvez até mesmo antes. $\mathrm{O}$ que estas comunidades de diversas origens têm em comum, fora sua 'negritude', é uma resistência de longas décadas, em um território que exploram (geralmente pela caça, pesca e agricultura de subsistência) sem subdivisões e sem escritura oficial. (PRICE, 1999).

É assim que a herança colonial do genocídio e opressão, "não se dissolveu com as independências das colônias, mas permaneceu ao longo do tempo se revestindo de diferentes roupagens." (ISOLDI, 2010, p. 10; 23).

Nos séculos XIX e XX, as populações descendentes de africanos ainda carregaram o peso da herança escravista, que as relegou às piores condições de vida durante o processo de modernização conservadora dos países latino-americanos e caribenhos.

Se a escravidão foi cruel para os milhões de negros raptados e contrabandeados para o continente e para sua descendência, o período 
pós-escravocrata não foi muito diferente. Assim, os mais de três séculos e meio de escravidão comprometeram a vida dos descendentes dos negros tendo reflexos irrefutáveis até os dias atuais. (NASCIMENTO; OLIVEIRA; 2016, p. 2)

Ou seja, no período pós-abolição da escravatura verificou-se a manutenção da contínua subjugação, desigualdade, exclusão e anulação da população negra. Mesmo que tenham deixado de exercer o trabalho escravo, não passaram a fazer parte da sociedade como trabalhadores. No caso dos povos quilombolas, ausente uma política integracionista, paulatinamente, muitos foram destituídos da posse de terras, sem trabalho digno, sem acesso à educação, enfrentando um cruel processo de exclusão e condenação à miséria e à segregação sócio-espacial. (ISOLDI, 2010, p. 20-21).

A antropóloga Laura Cecília López recorda havia entre os países da América Latina no período pós-colonial um objetivo comum quanto à formação populacional. Refere que "a constituição dos Estados nação nas Américas se deu num cenário de geopolíticas globais de raça, que tinham como horizonte o embranquecimento da nação". (LÓPEZ, 2015, p. 57).

Nesse contexto, a história do movimento negro - e também indígena - na América Latina, esteve marcada por “fugas, agrupamentos, revoltas e distintas lutas” (BALDI, 2016, p. 203). Não se deu sem "resistência às conjunturas adversas em que os negros afro-latinoamericanos estavam - e ainda estão - submetidos, condições essas, presentes em todo processo de escravidão e servidão" (NASCIMENTO; OLIVEIRA, 2016, p. 3).

Identifica-se que somente a partir da década de 1970, as causas coletivas antirraciais encontraram um cenário mundial mais favorável (LÓPEZ, 2015, p. 59), com o florescimento do movimento quilombola e das populações tradicionais através de novos movimentos sociais reivindicatórios dos direitos cidadãos. (ISOLDI, 2010, p. 29).

Especificamente na década de 1980, foi quando as mudanças legais iniciaram a ser efetivadas, com a inserção e reconhecimento de direitos relativos às populações etnicamente diferenciadas. Vários países da América Latina, dentre eles, "Brasil, Colômbia, Equador, Guatemala, Honduras e Nicarágua estenderam alguns direitos coletivos a comunidade negra" e grupos indígenas, e com isso, passaram a reconhecer sua origem na cidadania multicultural, como nações formadas a partir de povos distintos. (HOOKER, 2006, p.90).

Esse momento histórico caracteriza, de acordo com Donna Lee Van, o modelo da cidadania multicultural, incluindo cinco direitos coletivos obtidos através de reformas estatais internas:

[...] reconhecimento formal de subgrupos étnicos ou raciais específicos e da natureza multicultural das sociedades nacionais; reconhecimento do direito consuetudinário como direito público oficial; direitos de propriedade coletiva (especialmente em relação à terra); status oficial para a língua de minorias em regiões em que estas predominam; e garantia de educação bilíngüe. (2000a apud HOOKER, 2006, p. 89).

É assim que através de reformas legais internas, muitos países latino-americanos "asseguraram pelo menos um e, em muitos casos, todos esses direitos coletivos no direito constitucional ou estatutário", além de terem, em grande parte, ratificado a Convenção 169 da 
Organização Internacional do Trabalho (OIT) sobre os Direitos dos Povos Indígenas e Tribais, assumindo-se assim, a origem pluriétnica. (HOOKER, 2006, p.89-90)

A Colômbia, em sua Constituição de 1991, assegurou o direito à terra dos afrocolombianos, o qual foi regulamentado pela Lei 70 de 1993 e Lei 397 de 1997 . A Constituição brasileira desde 1988 garante às comunidades descendentes dos quilombos proteção de seus "modos de criar, fazer e viver" (artigos 215 e 216) e a propriedade de suas terras (artigo 68 do ADCT). No Equador, a Constituição de 1998 já reconhecia aos afroequatorianos direitos coletivos às suas terras, e a nova Constituição de 2008 reafirma tais direitos. O Equador conta também com a Ley de los Derechos Colectivos de los Pueblos Negros o Afroecuatorianos de 2006 que assegura os direitos dos povos negros sobre as suas terras ancestrais.

A Constituição da Nicarágua de 1987 garante às "comunidades da costa atlântica" as formas comunais de propriedade das terras e o procedimento para titulação dessas terras está regulamentado pela Lei 445 de 2002. Em Honduras a Ley de Propiedad de 2004 reconhece o direito dos afro-hondurenhos a suas terras e especifica que as mesmas devem ser tituladas de forma coletiva.

Nessa linha, observa-se um processo mais recente de luta por seus direitos, de homens e mulheres quilombolas, cuja atuação inclui a resistência contra a invisibilidade, a pobreza, o estigma, a discriminação, presentes desde o processo de escravidão do povo africano. Contudo, observa-se também que "os Estados-nacionais, alicerçados pelo pensamento conservador, ainda que tenham admitido mudanças nas legislações, não efetivaram transformações estruturais em relação à subalternização de grandes camadas da população." (ISOLDI, 2010, p. 30) O reconhecimento formal não tem sido suficiente para a efetivação dos direitos do povo quilombola.

Juliet Hooker (2006, p. 93) em reflexão feita sobre direitos coletivos conquistados pelo movimento negro e indigenista nas últimas décadas, considera alguns fatores: a) as reformas neoliberais e ajustes econômicos, interferiram no meio de vida dessas populações, desencadeando uma crescente mobilização étnica; b) a implementação legal como forma de legitimação interna do Estado, num momento em que se enfrenta dificuldades para satisfazer as demandas materiais de seus cidadãos; c) ou ainda, para deslegitimar reivindicações mais radicais.

A referida autora ainda aponta que "os regimes de cidadania multicultural da América Latina" resultaram de decisões tomadas pelas elites nacionais, com a finalidade de reconhecimento e fortalecimento da adesão democrática num período de transição do autoritarismo. Trata-se de uma forma de legitimação estatal, já que "a incapacidade dos governos latino-americanos de aprimorar o bem-estar material de seus cidadãos e de assegurar a igualdade perante a lei gerou uma crise de legitimidade do Estado", de modo que a implementação de uma política multiétnica poderia apontar para uma tentativa de solução ao problema da exclusão social e dos direitos democráticos.

O recurso à etnia como ideologia ou como apelo para a legitimação e coesão de um grupo pode ser usado tanto para fins eleitorais quanto para a guerra. Porém, tratar a etnia apenas como ferramenta para atingir objetivos eleitorais, ou para consolidar uma base social de apoio para a guerra, ou mesmo para buscar recursos de poder, é 
subestimar o apego que as pessoas efetivamente têm à sua identidade. (HOOKER, 2006, p. 100).

Desse modo, o contexto político em que os movimentos quilombolas estão inseridos "é o do surgimento dos direitos étnicos e coletivos" (ISOLDI, 2010, p. 30) ou mais ainda, de um "movimento de construção de identidade e luta contra a discriminação racial" (GOHN, 2010, p. 109), que tem desafiado as ordens locais, nacionais e internacionais.

A defesa dos direitos das comunidades negras já alcançou o sistema interamericano de direitos humanos, através de casos julgados pela Corte IDH envolvendo comunidades quilombolas do Suriname, de Honduras e Colômbia. Assim, identifica-se que a efetivação dos direitos das comunidades quilombolas permanece como um desafio aos países latinoamericanos, conforme se verificará ao longo do presente trabalho.

\section{OS CASOS ENVOLVENDO QUILOMBOLAS NA CORTE INTERAMERICANA DE DIREITOS HUMANOS}

Indubitável a constatação de que as conquistas normativas obtidas pelo movimento quilombola desde a década de 1980 nos países latino-americanos, são reflexos da uma resistência histórica dos quilombos e da luta pelo reconhecimento de sua identidade, de seus direitos culturais por parte do Estado.

Contudo, a real efetivação dos direitos dos povos quilombola tem sido um desafio para o início do século XXI. As práticas de dominação, as atitudes discriminatórias enraizadas e as concepções estereotipadas de papeis individuais na sociedade, muitas vezes impregnadas na própria linguagem normativa, tem sido analisadas pela Corte IDH, conforme os casos que chegaram ao seu conhecimento e apreciação. Os casos julgados pela Corte IDH tem uma mesma matriz de identificação, que diz respeito "a opressão dos habitantes originários e dos povos que foram levados como força de trabalho para estas regiões, no caso majoritariamente os africanos escravizados". (LÓPES, 2015, p. 56).

Destacam-se cinco casos envolvendo quilombolas: dois casos foram movidos contra o Suriname, outros dois casos contra Honduras e um caso envolveu a Colômbia. Para melhor conhecimento dos fatos, inicia-se com a contextualização das experiências vividas por cada uma das comunidades analisadas.

Nos casos envolvendo o Suriname, importante que se esclareça que os mesmos incluem a mobilização de dois (Comunidad Moiwana ${ }^{3}$ e Pueblo Saramaka) dos seis grupos negros Maroons ${ }^{4}$ que habitam e constituem a população do Suriname e, inclusive, a Guiana Francesa. Conforme o histórico analisado pela Corte IDH sobre a ancestralidade dessas comunidades, identificou-se que os mesmos são de origem africana, trazidos e mantidos em regime de escravidão, desde o século XVII, que em processo de fuga, foram criando pequenas e novas comunidades autônomas. ${ }^{5}$ As comunidades Maroons no Suriname viveram por

\footnotetext{
${ }^{3}$ A aldeia de Moiwana fui fundada por um clã N'djuka, no fim do século XIX. Informação extraída do parágrafo 86.11 da sentença do Caso de la Comunidad Moiwana. Disponível em < http://www.corteidh.or.cr/docs/casos/articulos/seriec_124_esp1.pdf>. Acesso em 07/09/2017

${ }^{4}$ Os Maroons integram seis grupos: N'djuka, Matawai, Saramaka, Kwinti, Paamaka e Boni ou Aluku. Fonte: parágrafo 86.1 da sentença do Caso de la Comunidade Moiwana. Disponível em < http://www.corteidh.or.cr/docs/casos/articulos/seriec_124_esp1.pdf>. Acesso em 07/09/2017 5 Informações extraídas do parágrafo 86.1 da sentença do Caso de la Comunidade Moiwana. Disponível em < http://www.corteidh.or.cr/docs/casos/articulos/seriec_124_esp1.pdf >. Acesso em 07/09/2017
} 
muitos anos em total independência do Estado, com plena autonomia. Ao longo desse período, vários foram os acordos e tratados firmados entre os quilombolas e os poderes coloniais da região, com vistas na manutenção à boa convivência. (REBELO, 2011, p. 95, 103).

Contudo, desde a metade do século XX, passaram a sofrer incursões em seus territórios, de forma atentatória a sua sobrevivência. Especialmente a partir da independência do Suriname do governo holandês, em 1975, emergiu uma política mais militante e agressivas contra os quilombolas e comunidades indígenas, a qual se fortaleceu durante a ditadura militar de Desi Bourtese, que perdurou por longo período da década de 1980, quando centenas de civis foram assassinados sendo seus direitos fundamentais repetidamente violados. (PRICE, 1999).

Assim, foi em meio a essa contextualização histórica, especialmente a partir da metade do século $\mathrm{XX}$, de crescente atentado contra as populações tradicionais, de viverem e reproduzirem conforme seus costumes ancestrais, bem como, de manterem suas raízes culturais, que a comunidade Moiwana e a Saramaka, por seus motivos específicos de violação de direitos humanos, ingressaram com demandas contra o Suriname no Sistema Interamericano de Direitos Humanos.

Com relação às demandas promovidas em face de Honduras, a contextualização dos fatos inclui um discurso de inclusão nas sociedades nacionais e ao mesmo tempo de discriminação estrutural do ordenamento interno originado no período colonial, que mantém formas de exclusão social e discriminação do povo Garífuna. Estes povos são fruto de uma miscigenação de escravos africanos e índios caribenhos, que após o naufrágio de dois navios negreiros, no início do século XVII, iniciaram o povoamento das costas caribenhas de quatro países (Honduras, Belize, Guatemala e Nicarágua), fator que facilitou uma de suas características, a mobilidade e circulação, sendo que até hoje ativam vínculos filiais entre "grupos de famílias dispersas presentes nos diferentes países". (AGUDELO, 2011, p. 52; 56). Honduras é o país com a maior concentração de Garífunas e já "em 1825, a Constituição Nacional de Honduras se refere a eles como morenos livres." 6 Essa é uma das particularidades do povo Garífuna, visto que "em Honduras a principal preocupação dos Garífunas era que não lhes atribuíssem um passado escravo", em que pese, apresentassem "traços fenotípicos africanos". (AGUDELO, 2011, p. 57; 58).

Ou seja, o povo Garífuna tem desenvolvido sua afirmação identidária sob diversas variantes de categorias raciais, ora indígena, ora negra, associada também à afirmação cidadã de pertencimento nacional, aspectos que tem sido estrategicamente utilizados na "articulação de suas reivindicações tanto em contextos nacionais como transnacionais." A partir dos anos de 90 do século passado, com o início do reconhecimento das populações negras ou de origem africana na América do Sul, que a dinâmica do povo garífuna de Honduras passa por transformações, que salientam suas "raízes e 'africanidade", além de incorporarem "às redes de mobilização transnacional dos movimentos negros da América Latina e do Caribe", com a finalidade de "impulsionar as transformações sociais e políticas reinvindicadas por eles" (AGUDELO, 2011, p. 53, 62-63)

Em um contexto de processos estruturais de debilidade e enfraquecimento traduzidos em marginalidade histórica em relação às sociedades nacionais, pobreza crescente e perda de territórios, o povo Garífuna "continua adotando em suas diferentes expressões a opção de insistir na afirmação de suas identidades como mecanismo de conquista da inclusão social." (AGUDELO, 2011, p. 69)

\footnotetext{
${ }^{6}$ Os Garífunas também receberam outras denominações como caribe negro, caribes morenos, morenos, conforme estudo apresentado por Carlos Agudelo, 2011.
} 
Como decorrência da "ineficiência e cumplicidade" dos órgãos judiciais de Honduras, quatro comunidades Garífunas apresentaram peticionamento junto a Comissão IDH: Casos de San Juan, Triunfo de la Cruz, Punta Piedra e Cayos Cochinos. Apenas os Casos Triunfo de la Cruz e de Punta Piedra foram encaminhados à Corte IDH. (CUISSET, 2014, p. 105). ${ }^{7}$

Por fim, no caso analisado pela Corte IDH envolvendo a Colômbia, identifica-se que os fatos ocorreram "no contexto do conflito armado colombiano, caracterizado pela sua extrema violência"8 e pela atuação de grupos ilegais que procuravam acesso pelos rios para o trafico de armas e drogas, bem como, pela expansão e controle territorial por esses grupos paramilitares. Na Colômbia, a região do rio Cacarica é habitada principalmente por descendentes de africanos submetidos à escravidão na época colonial. Essas populações foram se organizando em comunidades e assentaram-se ao longo dos rios da região. Conforme informações extraídas do caso, a população assentou-se nesse local como decorrência do processo de busca de terras, logo após a abolição da escravatura, em meados do século XIX. ${ }^{9}$

Apresentadas breves contextualizações dos casos analisados, passa-se a análise de cada um dos casos. O primeiro deles, Caso de la Comunidad Moiwana Versus Suriname, foi julgado pela Corte IDH em 15 de junho de 2005. O pedido de responsabilização do Suriname junto à Corte teve origem em fatos ocorridos a partir de 29 de novembro de 1986, quando as Forças Armadas desse país, atacaram a comunidade Moiwana, assassinando 39 membros da aldeia, incluindo crianças, mulheres, idosos, além de vários outros feridos. A referida operação também destruiu a infraestrutura da aldeia, cujos integrantes foram obrigados a abandoná-la em busca de proteção em outros locais da região e a sobreviver em condições de extrema pobreza. ${ }^{10}$ As consequências do ataque militar foram devastadoras, tendo o povoado ficado proibido de manter sua rotina de vida e meios tradicionais de subsistência ${ }^{11}$. Além disso, os familiares dos falecidos foram impossibilitados de recuperar os restos mortais de seus parentes e por consequência, promover os ritos religiosos próprios da cultura da comunidade. $^{12}$

O segundo caso, Caso del Pueblo Saramaka Versus Suriname foi julgado pela Corte IDH em 28 de novembro de 2007. O caso refere-se à responsabilidade internacional do Suriname por não adotar medidas efetivas que reconheçam os direitos de propriedade comunal do povo Saramaka, bem como a falta de recursos judiciais e administrativos

\footnotetext{
${ }^{7}$ Em pesquisa realizada na jurisprudência da Corte IDH, pelo site de pesquisa, identificou-se mais uma Comunidade Garífuna que apresentou petição junto a Corte, a Comunidad Garífuna de Barra Vieja, contudo seu requerimento junto à Corte IDH inclui apenas o procedimento de Medida Provisória, procedimento admitido pela Convenção Americana, no art. 63.2, ainda que não tenha sido iniciado uma reclamação específica junto à Comissão. Em decisão sobre o caso, conforme a resolução da Corte publicada em 14 de outubro de 2014, o pedido liminar da Comunidad Garífuna de Barra Vieja foi rejeitado. <http://www.corteidh.or.cr/CF/Jurisprudencia2/index.cfm?lang=es> Acesso em 20/09/2017.

8 Informação extraída de informativo do CEJIL. Disponível em <https://sidh.cejil.org/pt/entity/qpjjdgahi307ldi> Acesso em 02/10/2017.

${ }^{9}$ Informações extraídas do parágrafo 85 da sentença da Corte IDH do caso das Comunidades afrodescendientes desplazadas de la cuenca del río Cacarica (Operación Génesis) vs. Colombia. Download disponível em < www.corteidh.or.cr/docs/casos/articulos/seriec_270_esp.pdf> Acesso em 20/09/2017.

${ }^{10}$ Informação extraída do parágrafo 3 da sentença da Corte IDH do caso da Comunidade Moiwana contra Suriname. Tradução nossa. Disponível em: < http://www.corteidh.or.cr/docs/casos/articulos/seriec_124_esp1.pdf> Acesso em 07/09/2017.

${ }^{11}$ Informações extraídas do parágrafo 86.19 da sentença da Corte IDH do caso da Comunidade Moiwana.

${ }^{12}$ Informações extraídas do parágrafo 86.20 da sentença da Corte IDH do caso da Comunidade Moiwana.
} 
adequados e efetivos para enfrentar essa situação. O povo Saramaka é descendente de africanos vendidos como escravos em fins dos séculos XVII e XVIII e compõe um dos seis grupos negros Maroons que formam a população do Suriname. No ano de 1762, tiveram sua liberdade reconhecida, através de um tratado com a Coroa holandesa e desde então, viviam com total autonomia, "quase como um Estado a parte dentro do Estado do Suriname." (REBELO, 2011, p. 98). A partir de meados do século XX, e especificamente a partir do período anterior à independência, "o ritmo das incursões ao território habitado por esse grupo se alargou". Os territórios saramakanos passaram a ser visados para a construção de barragens e uma usina hidrelétrica. Assim, foi em razão de reiterada invasão ao território ocupado secularmente pelos Saramakas que em 27 de outubro de 2000, foi apresentada denúncia perante à Comissão IDH, por um grupo de doze clãs Saramakas, com a finalidade de assegurar proteção aos seus direitos sobre a terra. (REBELO, 2011, p. 103, 98-99)

O terceiro caso foi julgado pela Corte em 20 de novembro de 2013 e versou sobre as Comunidades Afrodescendentes deslocadas da Bacia do Rio Cacarica (Operação Génesis) contra a Colômbia. O caso refere-se às violações aos direitos humanos ocorridas em razão de atos praticados por integrantes das forças militares, através da "Operação Génesis", e aqueles praticados por unidades paramilitares, que atuaram na chamada "Operação Cacarica". O desenvolvimento de ambas operações, especialmente entre 24 e 27 de fevereiro de 1997, ao longo das margens do Rio Cacarica, área próxima aos territórios das comunidades afrodescendentes, teve seu ápice com a morte do Sr. Marino López Mena e o deslocamento forçado de centenas de afrodescendentes que tinham suas propriedades na região. Por conta desse episódio, bem como, pelo fato de a população afrodescendente que habitava a região do rio Cacarica ser obrigada a conviver com grupos armados à margem da lei, vivendo sob ameaças, mortes e desaparecimentos, vários povoados da bacia do rio, foram abandonados, dispersando-se a população em diversos assentamentos. Por pelo menos quatro anos, viveram em condições precárias, sem qualquer auxílio do governo. Quando alguns conseguiram retornar para as comunidades, permaneciam sendo alvo de hostilidades, ameaças e violência por parte de grupos paramilitares. ${ }^{13}$ Ao longo de toda a tramitação processual, ficou comprovado que as ações na bacia do Rio Cacarica ocorreram através da atuação conjunta da força pública, através da execução da Operación Génesis e forças paramilitares que executaram a Operación Cacarica. ${ }^{14}$, comprovada esta situação a Corte atribuiu os atos ao Estado em razão da anuência ou colaboração no andamento da última operação. ${ }^{15}$

Já o Caso Comunidad Garífuna Punta Piedra e seus membros contra Honduras julgado pela Corte IDH em oito de outubro de 2015 - se refere à responsabilidade internacional deste país pela violação do direito de propriedade e do dever de garantia do título de propriedade emitido em 1993 e 1999 pelo Estado à referida Comunidade. A ausência de delimitação e demarcação do território comunal, inviabilizou o uso e gozo da totalidade do território, fato que fragilizou o direito da comunidade à preservação de seu espaço contra a invasão de terceiros, criando um ambiente de hostilidade, insegurança e violência. Por volta

\footnotetext{
${ }^{13}$ Informações extraídas de extrato de jurisprudência (ficha técnica) emitida pela Corte IDH sobre o caso das Comunidades afrodescendientes desplazadas de la cuenca del río Cacarica (Operación Génesis). Disponível em http://www.corteidh.or.cr/cf/Jurisprudencia2/ficha tecnica.cfm?nld Ficha=377\&lang=es> Acesso em 20/09/2017.

${ }^{14}$ Informações extraídas do parágrafo 280 da sentença da Corte IDH do caso das Comunidades afrodescendientes desplazadas de la cuenca del río Cacarica (Operación Génesis). Disponível em $<$ www.corteidh.or.cr/docs/casos/articulos/seriec_270_esp.pdf> Acesso em 20/09/2017.

${ }^{15}$ Informações extraídas do parágrafo 290 da sentença da Corte IDH do caso das Comunidades afrodescendientes desplazadas de la cuenca del río Cacarica (Operación Génesis).
} 
de 1920, foi concedido à Comunidade Garífuna de Punta Piedra, um título judicial de uso e gozo de um terreno de aproximadamente 800 hectares. No ano de 1992 foi requerido o reconhecimento de propriedade desse território, e em 1999, sua ampliação. ${ }^{16}$ Contudo, durante o processo de titulação, foi informada a ocupação ilegal sobre seu território por terceiros (Comunidad Rio Miel, instalada nas proximidades do Rio Miel, dentro do território Garífuna), motivo que originou o problema sobre a titularidade das terras. ${ }^{17}$ Desde o ano 2001 ocorreram várias tentativas de resolução do conflito entre as duas Comunidades, sendo que o Estado havia expressamente se comprometido em adotar medidas para solução pacífica do problema. ${ }^{18}$ No entanto, durante vários anos, o conflito entre as duas comunidades perdurou e gerando um clima de violência, ameaças e hostilização entre os povoados, culminando com a ação judicial internacional.

Finalmente, o Caso Comunidad Garífuna Triunfo de la Cruz e seus membros contra Honduras - julgado pela Corte IDH em oito de outubro de 2015) - pede a declaração de responsabilização internacional deste país pela violação do direito de propriedade desta comunidade garífuna, por violação do dever de garantia do uso e gozo dos territórios que ela outorgados como territórios tradicionais, bem como, pela violação ao direito de propriedade por não ter sido efetuada nenhuma consulta prévia, nem estudo de impacto ambiental, sobre os projetos turísticos desenvolvidos no território da comunidade. Os processos de reconhecimento e titulação iniciaram-se do território Garífuna Triunfo de la Cruz $^{19}$, a partir da década de cinquenta do século passado, sendo que apesar do reconhecimento formal do Estado quanto a existência de áreas correspondentes ao território desta comunidade, ela acabou por se deparar situações rotineiras que atentavam contra os limites, uso e gozo pleno seu território. A Corte IDH, reconheceu a violação ao direito à propriedade coletiva (art. 21 da Convenção Americana) e a responsabilidade de Honduras por não cumprir sua obrigação de delimitar e demarcar as terras de titularidade reconhecida administrativamente como território tradicional; ${ }^{20}$ bem como, por não ter realizado um processo adequado para garantir o direito à consulta da Comunidade Garífuna Triunfo de la Cruz, quando das autorizações para implantações de projetos turísticos e formação de área protegida. $^{21}$

\section{O PAPEL DOS MOVIMENTOS SOCIAIS NA CONSTRUÇÃO E EFETIVAÇÃO DOS DIREITOS HUMANOS}

A realidade vivenciada desde a última década do século $\mathrm{XX}$, especialmente pela prevalência do enfoque econômico sobre os direitos fundamentais, determinou o surgimento

\footnotetext{
${ }^{16}$ Informações extraídas do parágrafo 92 da sentença da Corte IDH do caso Comunidad Garífuna de Punta Piedra y sus membros. Disponível em <www.corteidh.or.cr/docs/casos/articulos/seriec_304_esp.pdf>. Acesso em 07/09/2017.

${ }_{17}$ Informações extraídas do parágrafo 102 da sentença da Corte IDH do caso Comunidad Garífuna de Punta Piedra y sus membros.

${ }^{18}$ Informações extraídas do parágrafo 113 da sentença da Corte IDH do caso Comunidad Garífuna de Punta Piedra y sus membros.

${ }^{19}$ Conforme análise da Corte, foram apresentados requerimentos de titulação de propriedade e ampliação de área pela Comunidade Garífuna Triunfo de la Cruz nos anos de 1946, 1969, 1997, 1998 e 2001 .

${ }^{20}$ Informações extraídas do parágrafo 153 da sentença da Corte IDH do caso Comunidad Garífuna Triunfo de la Cruz y sus membros. Disponível em < http://www.corteidh.or.cr/docs/casos/articulos/seriec_305_esp.pdf>. Acesso em 07/09/2017.

${ }^{21}$ Informações extraídas do parágrafo 182 da sentença da Corte IDH do caso Comunidad Garífuna Triunfo de la Cruz y sus membros.
} 
de uma compreensão crítica à concepção de democracia e cidadania representativas. Identificou-se a necessidade de uma atuação mais ampla e sólida, vinculada à ideia de democracia mediante efetiva participação em instâncias diversas de deliberação e decisão, sejam elas estatais ou da sociedade civil. Maria da Glória Gohn, teórica e pesquisadora brasileira sobre temas como movimentos sociais, participação, associativismo e cidadania, refere que desde a metade dos anos 80 ocorreram mudanças na conjuntura política, tanto nacional quanto internacionalmente ${ }^{22}$, ponderando que as transformações

mais significativas foram na conjuntura econômica, com a estruturação e o rápido crescimento da globalização, elevando à reestruturação produtiva das nações, ao desemprego, e às reformas estatais orientadas para reequilibrar a crise fiscal, balança de pagamento etc." (GOHN, 2005, p.53).

A autora enfatiza o surgimento de novas características envolvendo as relações políticosociais internas. O papel do Estado teria passado por uma reestruturação, assumindo uma função essencialmente gerencial e administrativa de recursos, conduzindo "à privatização de serviços essenciais, à emergência de novos parceiros no atendimento de questões sociais, e à estratificação desse entendimento segundo os imperativos da lógica do mercado." Esse encolhimento do Estado, teria levado, portanto, "a uma diminuição da esfera social onde se desenvolve a cidadania plena", assim compreendida pela autora como aquela "moldada na tradição republicana, que pressupõe o conhecimento e a consciência ética dos processos políticos da pólis e do mundo em que se vive." (GOHN, 2005, p. 11, 29).

Nesse novo cenário, paralelamente, emergem "vários atores sociais" (GOHN, 2014, p. 22) que entraram em cena. A medida que o contexto sócio-político interno estava voltado ao pragmatismo econômico, aos projetos e acordos de perfil neoliberal, com preocupações táticas que resolvam problemas técnicos da economia, ocorre a emergência de novos atores, sujeitos sociais, antes organizados em movimentos e ações coletivas de protestos, agora com enfoque propositivo em múltiplas pautas de discussões.

A referida autora avança sobre o tema, afirmando que na atualidade, os movimentos sociais estão voltados para novas culturas políticas, de inclusão e contra a exclusão, em que as diferenças e multiculturalidades são consideradas para a construção de sua própria identidade e reconhecimento da diversidade cultural.

Há neles, na atualidade, uma ressignificação dos ideais clássicos de igualdade, fraternidade e liberdade. A igualdade é ressignificada com a tematização da justiça social; a fraternidade se retraduz em solidariedade; e a liberdade associa-se ao princípio da autonomia - da constituição do sujeito, não individual, mas coletivo; autonomia entendida como inserção e inclusão social na sociedade, com autodeterminação, com soberania. (GOHN, 2003, p. 13-14).

A abordagem dessa temática no âmbito da América Latina, conforme a autora (GOHN, 2016, p. 24), implica o reconhecimento de um novo cenário, desde os anos 2000, que inclui a ampliação do foco para local/global, Norte/Sul; propostas teóricas pós-coloniais, e ainda, a emergência de "novas abordagens que destacam identidades e subjetividades coletivas, redes de pertencimento, laços de confiança etc.”(GOHN, 2016, p. 24-25)

\footnotetext{
${ }^{22}$ Nacionalmente ocorreu "a redemocratização do país; e internacionalmente, com a queda do muro de Berlim e a crise dos regimes socialistas do leste europeu". (GOHN, 2005, p..53). 
Acrescente-se a essa nova realidade, o fato de que "várias lutas sociais se internacionalizam rapidamente", realidade a qual estaria vinculada à tendência dos grupos e movimentos sociais organizados articularem-se em redes. (GOHN, 2010, p. 11)

O trabalho em rede, não é uma temática nova. De longa data foi identificada nas ciências exatas, nas ciências humanas e biológicas, na antropologia, até mesmo na geografia, com a ressignificação do conceito de territórios, quando se passou a falar em "redes territoriais que transpõem as fronteiras da nação." ${ }^{23} \mathrm{Com}$ isso, o movimento passa a "articular a heterogeneidade de múltiplos atores coletivos em torno de unidades de referências normativas, relativamente abertas e plurais", passando a compreender diversos "níveis organizacionais", desde os agrupamentos de base até as plataformas de lutas políticas mais amplas. (SHERER-WARREN, 2008, p. 515).

No que se refere aos movimentos sociais transnacionais ${ }^{24}$, embora fortemente vinculados com o âmbito estatal e doméstico, valem-se das redes para obter oportunidades políticas que os deslocam ao cenário internacional.

[...] as redes de movimentos desenvolvem seus processos mobilizatórios em espaços locais ou regionais, mas, de forma articulada buscam impacto midiático, visibilidade numa esfera pública ampliada, de modo a desenvolver estratégias políticas e propostas programáticas em torno de suas necessidades e de sua noção de direitos, conectando os espaços locais com espaços nacionais, regionais e internacionais. (SHERER-WARREN, 2008, p. 514)

Com base nessas premissas teóricas, pode-se compreender a importância dos movimentos sociais na luta pelos direitos humanos. Parte-se da ideia de que um movimento social é reconhecido pela sua identidade política e não como política de identidade. Maria da Glória Gohn esclarece que a concepção de movimento social parte da construção de sua própria identidade, a partir dos "interesses, identidades, subjetividades e projetos de grupos sociais" (GOHN, 2010, p. 41). Não é, contudo, uma identidade pré-constituída ${ }^{25}$ apenas porque tem uma etnia, um gênero ou uma idade. "O reconhecimento da identidade política se faz no processo de luta, perante a sociedade civil e política.” (GOHN, 2010, p. 32).

A autora ainda acrescenta:

O reconhecimento jurídico, construção formal de um direito, para que tenha legitimidade, deve ser uma resposta do Estado à demanda organizada. Deve-se tratar a questão da identidade em termos de um campo relacional, de disputas e tensões, um processo de reconhecimento da institucionalidade da ação, e não como um processo de institucionalização da ação coletiva, de forma normativa, com regras e enquadramentos, como temos observado nas políticas públicas no Brasil na atualidade. (GOHN, 2010, p. 32).

\footnotetext{
23 "As redes [...] se referem a um tipo de relação social e atuam segundo objetivos estratégicos e produzem articulações com resultados relevantes para os movimentos sociais e para a sociedade civil em geral. A análise das redes requer metodologias específicas para captar a força sócio-cultural e política que condensam. Existem redes de diferentes tipos: de sociabilidade [...], locais [...], virtuais

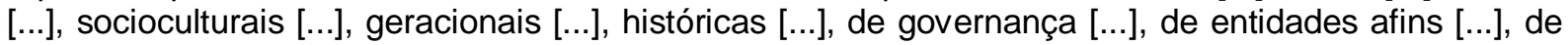
ONGs etc." (GONH, 2003, p. 15).

${ }_{24}$ Por transnacionalização, adota-se o conceito de Sidney Tarrow (2009, p.153): "refiro-me à cooperação de atores domésticos que trabalham juntos para além das fronteiras nacionais."

25 "reconhecimento outorgado, doado, uma inclusão de cima para baixo" (GOHN, 2010, p. 32)
} 
Nessa ótica, acrescentam-se os ensinamentos de Joaquín Herrera Flores, de que os direitos humanos são algo mais do que um conjunto de normas formais que os reconhecem e os garantem em nível nacional ou internacional. Enfatiza-se sua contribuição a partir de uma teoria crítica dos direitos humanos, com vistas a compreender os direitos humanos a partir de "práticas sociais emancipadoras". (HERRERA FLORES, 2009, p. 14). O autor (2004, p. 103, 104) também enfatiza a nova fase histórica que os direitos humanos vivenciam, especialmente desde o fim dos anos oitenta e princípios dos noventa do século passado, com a queda do socialismo e a consequente expansão global do modo de produção e de relações sociais capitalistas. Ou seja, entende que a globalização, no modelo neoliberal, caracteriza-se como a nova fase, e as características de apropriação do capital estão provocando uma mudança importante na conceituação dos direitos humanos.

A progressiva instauração de uma ordem global sustentada na apropriação do capital e o surgimento de uma consciência de injustiças e desequilíbrios conduzidos pela globalização, estão provocando o surgimento de processos de reação social, que não se conformam com as tradicionais formas de participação e articulação social. São essas reações compreendidas como processos de lutas que constituem o desafio da nova fase mundial para reconhecimento dos direitos humanos.

Não podemos entender os direitos sem vê-los como parte da luta de grupos sociais empenhados em promover a emancipação humana, apesar das correntes que amarram a humanidade na maior parte de nosso planeta. Os direitos humanos não são conquistados apenas por meio das normas jurídicas que propiciam seu reconhecimento, mas também, e de modo muito especial, por meio das práticas sociais de ONGs, de Associações, de Movimentos Sociais, de Sindicatos, de Partidos Políticos, de Iniciativas Cidadãs e de reivindicações de grupos, minoritários (indígenas) ou não (mulheres), que de um modo ou de outro restaram tradicionalmente marginalizados do processo de positivação e de reconhecimento institucional de suas expectativas. (HERRERA FLORES, 2009, p. 77)

Ou seja, na visão do jurista sevilhano, são as práticas sociais emancipatórias dos atores sociais que possibilitam um "intervencionismo humanitário", capaz de revigorar a construção de um "marco de ação que permita a todos e a todas criar as condições que garantam de um modo igualitário o acesso aos bens materiais e imateriais que fazem com que a vida seja digna de ser vivida." (HERRERA FLORES, 2009, p. 77; 25). Direitos humanos estão intrinsecamente vinculados com processos sociais e institucionais de luta, de modo a possibilitar aos indivíduos e grupos cumprir "desejos e necessidades" a partir de seus contextos vitais.(HERRERA FLORES, 2009, p. 77, 25).

Nesse aspecto, enfatiza-se a concepção de direitos humanos como reações, movimentos e evolução de circunstâncias históricas, que se fortalecem a partir de novas forças transformadoras, concepção essa que tem conexões com os movimentos sociais emancipatórios, assim compreendidos como mobilizações coletivas da sociedade, de natureza sócio-política ou cultural, que viabilizam formas de discussões e organizações de seus interesses e demandas.

Tanto Joaquín Herrera Flores como Maria da Glória Gohn, com suas contribuições teóricas, dão ênfase à importância do fortalecimento do diálogo crítico e emancipador a partir dos cidadãos em prol dos direitos que entendem indispensáveis a sua vida com dignidade. 
Assim, a partir desse referencial teórico, busca-se a identificação das características do movimento quilombola, que a partir de lutas históricas, tanto no regime colonial como póscolonial, abarca um movimento de reconhecimento pelo Estado de sua identidade própria, de seus direitos, de sua memória. Marcam um movimento de luta pela existência física, cultural, histórica e social com nítido enfoque emancipatório que pressupõe novas estratégias para efetivação de sua identidade e direitos.

\section{CONSIDERAÇÕES FINAIS}

O desenvolvimento da sociedade latino-americana esteve marcado pela exploração e ocupação de territórios, bem como, opressão e escravização, principalmente de negros trazidos forçadamente pelas metrópoles europeias. Esse histórico colonial esteve presente desde o início da formação dos Estados da América Latina, e os reflexos repercutiram sobre os descendentes de negros africanos mesmo após a abolição da escravatura. Nos séculos XIX e XX, as populações descendentes de africanos ainda carregaram o peso da herança escravista, que as relegou às piores condições de vida durante o processo de modernização conservadora dos países latino-americanos e caribenhos.

Acrescente-se que associado ao histórico de escravidão e servidão, o povo negro sempre esteve vinculado a vários movimentos de resistência, de sobrevivência paralela, quer com quilombos, revoltas, levantes, lutas, etc, sendo que essas mobilizações sempre estiveram presentes ao longo dos contextos históricos de cada época.

Foi especialmente a partir da década de 1980, que o movimento quilombola encontrou maior respaldo nas suas reivindicações, quando vários países da América Latina passaram a inserir e reconhecer os direitos de suas populações etnicamente diferenciadas, o que se fortaleceu com a homologação da Convenção 169 da OIT, em que os países automaticamente passaram a reconhecer a origem pluriétnica de suas sociedades.

Contudo, tem-se observado que embora admitidas mudanças nas legislações internas, o reconhecimento formal não tem sido suficiente para a efetivação dos direitos quilombolas. As práticas de dominação, as atitudes discriminatórias enraizadas e as concepções estereotipadas de papeis individuais na sociedade, muitas vezes impregnadas na própria linguagem normativa, tem sido analisadas pela Corte IDH, conforme os casos que chegaram ao seu conhecimento e apreciação envolvendo comunidades quilombolas do Suriname, de Honduras e Colômbia.

Analisando-se a temática a partir da contribuição de Maria da Glória Gohn, tem-se que na atualidade, os movimentos sociais estão voltados para novas culturas políticas, de inclusão e contra a exclusão, em que as diferenças e multiculturalidades são consideradas para a construção de sua própria identidade e reconhecimento da diversidade cultural.

Parte-se também, da ideia de que um movimento social é fortalecido quando reconhecido pela sua identidade política, como um processo de luta, perante a sociedade civil e jurídica.

Nessa lógica, acrescenta-se também a contribuição de Joaquin Herrera Flores, no sentido de ressaltar que a concepção de direitos humanos tem relação com processos de reações, movimentos e evolução de circunstâncias históricas, que se fortalecem a partir de novas forças transformadoras, concepção essa que tem conexão com os movimentos sociais emancipatórios, assim compreendidos como mobilizações coletivas da sociedade, de natureza sócio-política ou cultural, que viabilizam formas de discussões e organizações de seus interesses e demandas. 
E essa tem sido a característica do movimento quilombola, que a partir de lutas históricas, tanto no regime colonial como pós-colonial, abarca um movimento de reconhecimento pelo Estado de sua identidade própria, de seus direitos, de sua memória. Marcam um movimento de luta pela existência física, cultural, histórica e social, com nítido enfoque emancipatório que pressupõe novas estratégias para efetivação de sua identidade e direitos.

\section{REFERÊNCIAS}

AGUDELO. Os garífunas: transnacionalidade territorial, construção de identidades e ação política. Desigualdade \& Diversidade - Revista de Ciências Sociais da PUC-Rio, no ${ }^{\circ}$, janjul, 2011, pp. 51-76.

BALDI, César Augusto (Org.). Direitos Humanos na Sociedade Cosmopolita. Rio de Janeiro: Renovar, 2004.

BOLIVIA. Constitución (2009). Constitución Política del Estado. Disponível em < https://www.google.com.br/url? $\mathrm{sa}=\mathrm{t} \& \mathrm{rct}=\mathrm{j} \& \mathrm{q}=\& \mathrm{esrc}=\mathrm{s} \&$ source=web\&cd=1\&cad=rja\&uact= 8\&ved=0ahUKEwj79_2Tu6vYAhVMH5AKHUMIC8kQFggoMAA\&url=https\%3A\%2F\%2F www.oas.org\%2Fdil\%2Fesp\%2FConstitucion_Bolivia.pdf\&usg=AOvVaw11uxhCPl44K36zQ10RfxS>. Acesso em 03/12/2017.

BRASIL. Constituição da República Federativa do Brasil: promulgada em 5 de outubro de 1988. 54. ed., atual. e ampl. São Paulo: Saraiva, 2017.

COLOMBIA. Constitución (1991). Constitución Política de Colombia. Disponível em < http://www.corteconstitucional.gov.co/?bTy>. Acesso em 03/12/2017.

COMISSÃO INTERAMERICANA DE DIREITOS HUMANOS. Convenção americana sobre direitos humanos. Disponível em: < http://www.cidh.oas.org/basicos/portugues/c.convencao_americana.htm>. Acesso em 05/06/2017.

CORTE Interamericana de Direitos Humanos. Caso de la Comunidad Moiwana vs. Suriname. Disponível em <http://www.corteidh.or.cr/docs/casos/articulos/seriec_124_esp1.pdf >. Acesso em 07/09/2017

Caso del Pueblo Saramaka vs. Suriname. Disponível em

<http://www.corteidh.or.cr/docs/casos/articulos/seriec_172_esp.pdf> Acesso em 07/09/2017.

Caso das Comunidades afrodescendientes desplazadas de la cuenca del río Cacarica

(Operación Génesis) vs. Colombia. Download disponível em < www.corteidh.or.cr/docs/casos/articulos/seriec_270_esp.pdf> Acesso em 20/09/2017.

Caso da Comunidad Garífuna de Punta Piedra y sus miembros vs. Honduras. Disponível em < www.corteidh.or.cr/docs/casos/articulos/seriec_304_esp.pdf $>$. Acesso em 07/09/2017. 
Caso da Comunidad Garífuna Triunfo de la Cruz y sus miembros vs. Honduras. Disponível em < http://www.corteidh.or.cr/docs/casos/articulos/seriec_305_esp.pdf >. Acesso em 07/09/2017.

CUISSET, Olivier. Del campo a la ciudad y vice-versa: elementos para la historia del movimiento garífuna en Honduras. Revista de estudos jurídicos e pesquisas sobre as Américas. 2014, V.8, nº 1, p. 79-111.

FIABANI, Adelmir. Os novos quilombos: luta pela terra e afirmação étnica no Brasil [19882008]. 2008. 275f. Tese (Doutorado em História) - Programa de Pós-Graduação em História da Universidade do Vale do Rio do Sinos. São Leopoldo. 2008. Disponível em <http://www.repositorio.jesuita.org.br/handle/UNISINOS/2177> Acesso em 20/10/2017.

GOHN, Maria da Glória; BRINGEL, Breno M. (Orgs.) Movimentos sociais na era global. 2. ed. Petrópolis, RJ: Vozes, 2014.

Teoria dos movimentos sociais. Paradigmas clássicos e contemporâneos. $4^{\mathrm{a}}$. ed. São Paulo: Edições Loyola, 2004.

O protagonismo da sociedade civil: movimentos sociais, ONGs e redes solidárias. São Paulo: Cortez, 2005. 120 p.

Movimentos sociais e redes de mobilizações civis no Brasil contemporâneo. 2. ed. Petrópolis, RJ: Vozes, 2010.

Empoderamento e participação da comunidade em políticas sociais. Saúde e

Sociedade. v.13, n.2, p.20-31, maio-ago 2004

HERRERA FLORES, Joaquín. A reinvenção dos direitos humanos. Tradução de Carlos Roberto Diogo Garcia; Antonio Henrique Graciano Suxberger; Jefferson Aparecido Dias. Florianópolis: Fundação Boiteux e IDHID, 2009.

Los Derechos em el Contesxto de la Globalizacion; três precisiones conceptuales. SÁNCHEZ RUBIO, David; HERRERA FLORES, Joaquín; CARVALHO, Salo de (Org.). Direitos humanos e globalização: fundamentos e possibilidades desde a teoria crítica. 2. ed. Porto Alegre: EDIPUCRS, 2010. 578 p. Disponível em http://www.pucrs.br/edipucrs/direitoshumanos.pdf. Acesso em 07 de julho de 2016.

HONDURAS. Constituição 1982. Constitución de la Republica de Honduras 1982. Disponível em <http://pdba.georgetown.edu/Constitutions/Honduras/hond82.html>. Acesso em $03 / 12 / 2017$

HOOKER, Juliet. Inclusão indígena e exclusão dos afro-descendentes na América Latina . Tempo Social, São Paulo, v. 18, n. 2, p. 89-111, nov. 2006. Disponível em: <http://www.revistas.usp.br/ts/article/view/12516>. Acesso em: 06 de dezembro de 2017. 
ISOLDI, Isabel Araújo. Territorialidades negras no território nacional: processos sócioespaciais e normalização da identidade quilombola. 2010. 145f. Dissertação (Mestrado em Geografia) - Instituto de Geociências da Universidade Estadual de Campinas, SP, 2010. Disponível em http://repositorio.unicamp.br/jspui/handle/REPOSIP/287052 Acesso em 20/10/2017.

LÓPEZ, Laura Cecília. Movimentos afro-latino-americanos: unidos pela diáspora e contra a opressão (Entrevista). Revista Instituto Humanitas Unisinos. 2015, Ed. 477, p. 56-62, de 16-11-2015. Disponível em < http://www.ihu.unisinos.br/entrevistas/549313-movimentosafro-latino-americanos-unidos-pela-diaspora-e-contra-a-opressao-entrevista-especial-comlaura-cecilia-lopez>

NASCIMENTO, V. L. do; OLIVEIRA, M. R. N. S. O movimento negro na América Latina: Brasil e Colômbia. In: SIMPÓSIO INTERNACIONAL PENSAR E REPENSAR A AMÉRICA LATINA, II, 2016. São Paulo. Anais eletrônicos. Disponível em < sites.usp.br/prolam/wp-content/uploads/sites/35/2016/12/NASCIMENTO_SP01-Anais-do-IISimp\%C3\%B3sio-Internacional-Pensar-e-Repensar-a-Am\%C3\%A9rica-Latina.pdf> Acesso em 01/12/2017.

PRICE, Richard, Reinventando a história dos quilombos: rasuras e confabulações. Tradução de Gisela Moreau. Revista Afro-Ásia, Bahia, n. 23, 1999. Disponível em <http://www.redalyc.org/articulo.oa?id=77002308> Acesso em 02/10/2017

Quilombolas e direitos humanos no Suriname. Horizontes Antropológicos, Porto Alegre, ano 5, n. 10, p. 203-241, maio 1999. Disponível em <http://dx.doi.org/10.1590/S0104-71831999000100009> Acesso em 02/10/2017.

REBELO, M. de N. de O. O povo Saramaka versus Suriname: uma análise sob o olhar de Clifford Geertz. Cadernos da Escola de Direito e Relações Internacionais, Curitiba, 2011, vol. 1, no 14, p. 95-118. Disponível em <

http://revistas.unibrasil.com.br/cadernosdireito/index.php/direito/article/view/605>

SCHERER-WARREN, Ilse. Redes de Movimentos Sociais na América Latina - caminhos para uma política emancipatória? Caderno CRH, Salvador, v. 21, n. 54, p. 505-517, Set./Dez. 2008.

WOLKMER, Antonio Carlos. História do direito no Brasil. 9. ed. rev. e atual. Rio de Janeiro: Forense, 2015.

Introdução ao pensamento jurídico crítico. 9. ed. São Paulo: Saraiva, 2015.

Rey, 2014.

(Org.). Fundamentos de história do direito. 8. ed., rev. e ampl. Belo Horizonte: Del

; BRAVO, Efendy Emiliano Maldonado. Horizontes para se repensar os direitos humanos numa perspectiva libertadora. In: LEAL, Jackson da Silva; FAGUNDES, Lucas Machado (org.). Direitos humanos na América Latina. Curitiba: Multideia, 2016. 